\author{
ARTIGO \\ dol https://doi.org/10.22481/rpe.v16i43.7051
}

\title{
ARTE-EDUCAÇÃO E COMPUTADOR: TENDÊNCIAS E DESAFIOS
}

\author{
ART EDUCATION AND COMPUTER: TRENDS AND CHALLENGES
}

EDUCACIÓN ARTÍSTICA Y COMPUTADORA: TENDENCIAS Y DESAFÍOS

\author{
Carla Milbradt \\ Universidade La Salle - Brasil \\ Adilson Cristiano Habowski \\ Universidade La Salle - Brasil \\ Elaine Conte \\ Universidade La Salle - Brasil
}

\begin{abstract}
Resumo: $\mathrm{O}$ artigo busca compreender os desafios e as tendências no que diz respeito à sensibilização e articulação do computador para o ensino de Arte. Temos como horizonte as seguintes problematizações: Quais são os desafios e as tendências contemporâneas à articulação entre arte-educação-computador para os cenários de aprendizagem em Arte? Quais são os discursos e as preocupações presentes nas dissertações e teses produzidas na esfera da arte-educação e computador? Que percepções os professores têm em relação às experiências com o uso do computador nas aulas de Arte? Se as tecnologias nas interfaces da linguagem artística, da produção cultural e da vida cotidiana não cessam de nos provocar, por meio de práticas sociais e interações no mundo, quais questões emergem desse universo dialógico do conhecimento? Trata-se de uma pesquisa hermenêutica que propõe rastrear as produções referentes ao campo da arte-educação e computador, problematizando as tradições e instrumentos culturais e suas articulações nas escolas. Após um levantamento bibliográfico na Biblioteca Digital Brasileira de Teses e Dissertações (BDTD), para compreender as produções do campo, realizamos um estudo exploratório que levou em consideração as concepções de três professores que atuam em escolas e descrevem o horizonte da arte-educação nos cenários de uso do computador. Concluímos que o uso do computador para a criação artística no cotidiano escolar pode contribuir para o aperfeiçoamento didático da arteeducação pelo acesso às redes digitais, mas é na questionabilidade da experiência prática e no esforço educacional da reinvenção humana que o conhecimento das narrativas estéticas e da produção cultural ganha novas dimensões formativas e sociais.
\end{abstract}

Palavras chave: Arte-Educação; Computador; Escola; Abordagens didático-pedagógicas.

\begin{abstract}
The article seeks to understand the challenges and trends regarding the sensitization and articulation of the computer for the teaching of Art. Our horizon is the following problematizations: What are the challenges and contemporary trends to the articulation between art-education-computer for the learning scenarios in Art? What are the discourses and concerns present in the dissertations and theses produced in the sphere of art-education and computer? What perceptions do teachers have about experiences with computer use in art classes? If technologies in the interfaces of artistic language, cultural production and everyday life never cease to provoke us, through social practices and interactions in the world, what questions emerge from this dialogical universe of knowledge? This is a hermeneutic research that proposes to trace the productions related to the field of art-education and computer,
\end{abstract}


problematizing the traditions and cultural instruments and their articulations in schools. After a bibliographic survey at the Brazilian Digital Library of Theses and Dissertations (BDTD), to understand the productions of the field, we conducted an exploratory study that took into account the conceptions of three teachers who work in schools and describe the horizon of art-education in computer use scenarios. We conclude that the use of the computer for artistic creation in the school routine can contribute to the didactic improvement of art-education byaccess to digital, but it is in the questionability of practical experience and in the educational effort of human reinvention that the knowledge of aesthetic narratives and cultural production gains new formative and social dimensions.

Keywords: Art-Education; Computer; School; Educational approaches-pedagogic.

Resumen: El artículo busca entender los retos y tendencias con respecto a la sensibilización y articulación del ordenador para la enseñanza del Arte. Nuestro horizonte es la siguiente problemática: ¿Cuáles son los retos y tendencias contemporáneas a la articulación entre el arte-educación-ordenador para los escenarios de aprendizaje en el arte? ¿Cuáles son los discursos y preocupaciones presentes en las tesis y tesis producidas en el ámbito de la educación artística y la informática? ¿Qué percepciones tienen los maestros acerca de las experiencias con el uso de computadoras en las clases de arte? Si las tecnologías en las interfaces del lenguaje artístico, la producción cultural y la vida cotidiana nunca dejan de provocarnos, a través de prácticas sociales e interacciones en el mundo, ¿qué preguntas surgen de este universo dialogante del conocimiento? Se trata de una investigación hermenéutica que propone rastrear las producciones relacionadas con el campo de la educación artística y la informática, problemática de las tradiciones e instrumentos culturales y sus articulaciones en las escuelas. Después de una encuesta bibliográfica en la Biblioteca Digital Brasileña de Tesis y Tesis (BDTD), para entender las producciones del campo, realizamos un estudio exploratorio que tuvo en cuenta las concepciones de tres profesores que trabajan en las escuelas y describen el horizonte de la educación artística en escenarios de uso informático. Concluimos que el uso de la computadora para la creación artística en la vida escolar cotidiana puede contribuir a la mejora didáctica del arte-educación mediante el acceso a las redes digitales, pero es en la cuestionabilidad de la experiencia práctica y en el esfuerzo educativo de la reinvención humana que el conocimiento de la narrativa estética y la producción cultural adquiere nuevas dimensiones formativas y sociales.

Palabras clave: Arte-Educación; Computadora; La escuela; Enfoques didáctico-pedagógicos.

\section{Considerações iniciais}

\section{O computador ${ }^{1}$ é uma construção cultural com potencial para a promoção da imaginação} criadora e de novas sensibilidades no campo da arte-educação, causando a ruptura de modelos

\footnotetext{
${ }^{1} \mathrm{O}$ primeiro trabalho que conceitua a ideia moderna de computador também define um limite da computação (TURING, 1936). Para além da análise do que é um computador (dispositivo técnico controlado por um programa operacional, por tentativa e erro, para processar dados por componentes eletrônicos), é explorado aqui como uma tela de oportunidades ou ponte à percepção profunda da arte-educação. Abordar a Arte nesse campo de interfaces e experiências visuais com o computador mostra que os próprios cientistas não conceberam o computador como uma máquina a serviço de políticas capitalistas (simplificadoras e reificantes da identidade coletiva), mas como uma ferramenta artística que se destinava ao uso de sujeitos, artistas e professores para o desenvolvimento da criatividade humana (PETRY, 2009). Para aprofundar as questões sobre os usos do computador em práticas escolares por professores e estudantes, bem como em Programas Educacionais por Computador, consultar as dissertações de Boas (2014) e de Araujo (2018).
} 
educativos meramente instrumentais, pelas próprias mudanças que engendra, em resposta ao mundo visual em transformação, que valoriza a criatividade, as dimensões humanas, as diferenças e as singularidades das formas de linguagem, cujas expressões e interações possibilitam novos modos de aprender e reinventar em meio aos desafios da práxis dialógica. Em tempos de naturalização das tecnologias digitais na educação, como forma de promoção de aprendizagens, torna-se necessário compreender as relações da arte-educação com as abordagens práticas do uso do computador pelos professores de Arte, tendo em vista os enfoques teórico-práticos na produção de conhecimentos no cotidiano escolar.

Nesta perspectiva, desenvolvemos esta pesquisa partindo das seguintes problematizações: Quais são os desafios e tendências contemporâneas à articulação entre arteeducação-computador para os cenários de aprendizagem em Arte? Quais são os discursos e as preocupações presentes nas dissertações e teses produzidas na esfera da arte-educação e computador? Que percepções os professores têm em relação às experiências com o uso do computador nas aulas de Arte? Se as tecnologias nas interfaces da linguagem artística, da produção cultural e da vida cotidiana não cessam de nos provocar, por meio de práticas sociais e interações no mundo, quais questões emergem desse universo dialógico das culturas pesquisadas nas diferentes áreas do conhecimento?

Pretendemos contribuir para o debate em torno das inter-relações entre as produções mapeadas e as concepções dos professores de Arte que atuam nas escolas, a fim de tratar a questão de forma triangular e integradora, para responder às inquietações projetadas. Nesse sentido, debatemos as tendências no campo da arte-educação em relação às contradições e aos desafios do uso do computador na escola. Por fim, realizamos uma tentativa de triangulação dos dados obtidos pelo referencial teórico e pela conjugação das respostas dos professores, com o intuito de dar visibilidade ao que acontece nas escolas em relação às experiências educativas.

\section{Abordagem metodológica}

Esse estudo foi realizado por meio de uma abordagem hermenêutica para compreender o estado da arte sobre a temática e para mapear as pesquisas recentes sobre o assunto (CONTE; MARTINI, 2019). "A atitude hermenêutica desperta diferentes visões e discursos de mundo como questões inspiradoras e inquietantes para continuar o diálogo educativo com as diferenças e a pluralidade de formas de pensar, sentir e agir no mundo" (HABOWSKI; CONTE; PUGENS, 2018, p. 183). As aproximações da hermenêutica com a arte-educação são projetadas por Gadamer (2005), ao defender que a experiência da arte é um jogo em que o sujeito é levado a 
participar inspirado pela obra, que interpela e por isso a diversidade nas interpretações. A obra de arte amplifica e transforma a perspectiva do sujeito como um acontecimento que se apodera de nós (angústias do sujeito em face ao objeto) e faz sentido na abertura para o diálogo e para a descoberta de novas experiências. A partir da abordagem hermenêutica procuramos identificar as problemáticas, impactos e os desafios das artes com o estímulo do computador na educação, realizando um mapeamento de dissertações de mestrado e teses de doutorado produzidas em diferentes Programas de Pós-Graduação (PPG) das universidades do país. A arte é um fenômeno presente em todas as culturas e em diferentes áreas do conhecimento, por isso o rastreamento incluiu dissertações e teses produzidas em diferentes PPG e disponíveis no portal da Biblioteca Digital Brasileira de Teses e Dissertações (BDTD).

Procuramos apresentar em formato de eixos as pesquisas mapeadas, apontando os principais desafios e movimentos criativos do campo, discutindo o que foi encontrado em termos de convergências nas pesquisas, para compreender os sentidos dessa criação no mundo complexo, multifacetado e paradoxal das artes em meio aos computadores. Tal esforço investigativo busca dar visibilidade ao conjunto de dissertações e teses produzidas no Brasil sobre arte-educação e os sentidos atrelados ao computador no ensino da arte, que precisa ser construído a partir da liberdade - potencial inovador de percepção sensível da vida. A hermenêutica se justifica pela atitude de constante revisão e atualização de textos, linguagens e contextos sociais para se chegar a uma compreensão da realidade no próprio movimento dinâmico, fluído e dialético do mundo da vida.

Após a coleta e interpretação dos estudos mapeados, a investigação parte para uma segunda etapa que se refere ao envio de um questionário on-line aos professores de escolas públicas e privadas que atuam no ensino da Arte, para verificar as suas percepções da temática no momento da aplicação do conhecimento na práxis educacional. Os participantes da pesquisa que aceitaram o convite e assinaram o Termo de Consentimento Livre e Esclarecido (TCLE) responderam as perguntas enviadas e foram três (3) professores, que atuam no campo da arteeducação em diferentes escolas e aceitaram produzir reflexões acerca das percepções e ações desenvolvidas com as linguagens digitais. Estes professores desenvolvem práticas pedagógicas com computadores ou mobilizam diferentes experiências pedagógicas com os meios digitais na escola e foram denominadas nesse trabalho como Professora 1, Professor 2 e Professora 3. Tal atitude pressupõe situar as pesquisas da área, por meio do rastreamento de teses e dissertações, bem como desenvolver um estudo empírico com os professores, para contextualizar como são realizadas na prática escolar tais ações via computador no campo da arte-educação. A 
elaboração do questionário semiestruturado e a sua aplicação ocorreu por meio do Google Forms, de modo que os três professores participaram de forma voluntária da pesquisa.

Questões que compuseram a pesquisa, em termos de percepções e práticas dos professores:

1. O que você pensa a respeito do uso do computador na disciplina de Arte?

2. Os métodos tradicionais de ensino em Arte foram ressignificados com o computador na prática?

3. As mudanças com o acesso ao computador na disciplina de Arte influenciam a aprendizagem do educando?

4. Por que ainda é pouco explorado o uso do computador nas aulas de Arte?

5. Quais as vantagens e desvantagens do uso do computador nas aulas de Arte?

A partir desta interação com os professores no contexto escolar e do estabelecimento de pontes entre as pesquisas coletadas no campo, procuramos novas abordagens dialógicas dos processos de ensino com as tecnologias dando mais visibilidade ao que se reflete e se desenvolve na prática cotidiana da arte-educação no mundo escolar, que desvelam outras possibilidades para desenvolver a sensibilidade, a criatividade e a expressão humana e social.

\section{Trabalhos correlatos}

Nesta seção apresentamos o mapeamento das dissertações de mestrado e teses de doutorado produzidas nos diversos Programas de Pós-Graduação das universidades brasileiras, disponíveis no portal de domínio público da Biblioteca Digital Brasileira de Teses e Dissertações (BDTD). Foram encontradas cinquenta e cinco (55) dissertações e vinte e sete (27) teses de doutorado, totalizando oitenta e duas (82) pesquisas, a partir dos descritores arte e computador. Para este estudo, realizamos inicialmente um agrupamento entre os Programas em Pós-Graduação em Educação. Em seguida, identificamos em outros Programas de PósGraduação as pesquisas com interfaces entre arte, computador e educação. A partir desse corpus investigativo, podemos identificar a distribuição de instituições de origem dos trabalhos coletados, sendo que a instituição que mais realizou pesquisas na área foi a Universidade de Brasília (UnB), totalizando vinte e oito (28) trabalhos, seguida pela Pontifícia Universidade Católica de São Paulo (PUC-SP), somando onze (11) pesquisas. Podemos visualizar melhor no gráfico 1, a seguir, de todas as universidades. 
Gráfico 1 - Origem/quantidade de trabalhos por Universidade

\section{UNIVERSIDADES}

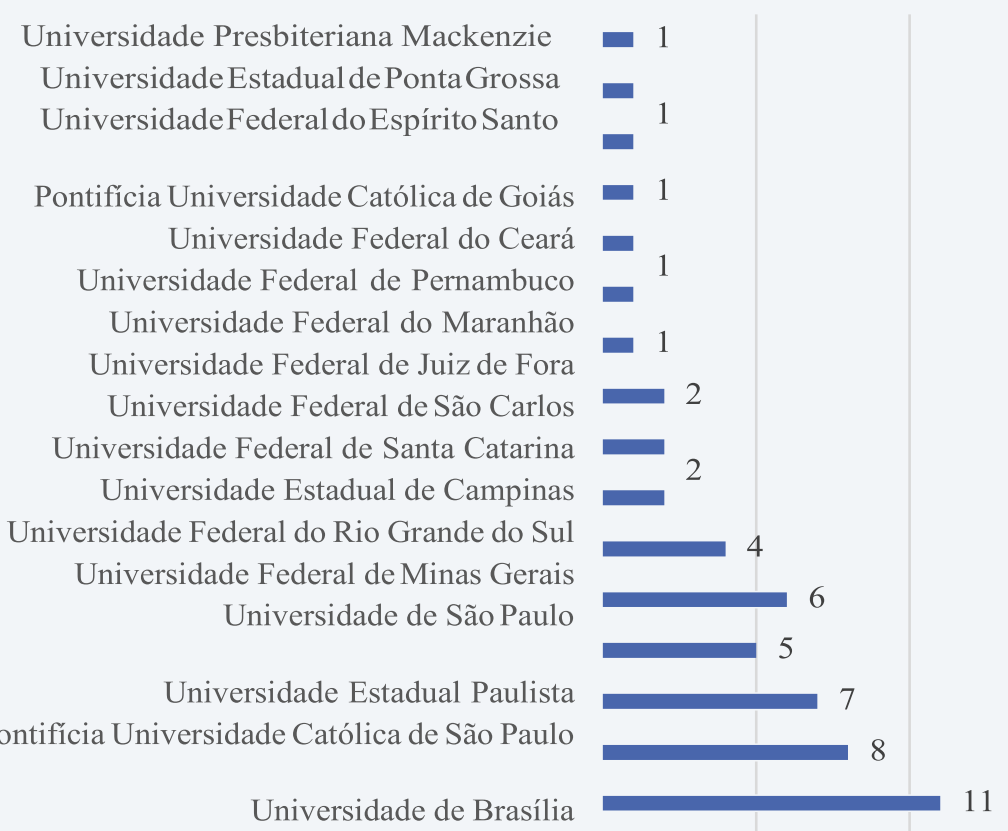

Fonte: Elaborado pelos autores (2020).

Agora, podemos verificar os Programas de Pós-Graduação em que as dissertações e teses foram defendidas. Elencamos: 21 Programas de Pós-Graduação em Arte; 18 Programas de Pós-Graduação em Artes; 6 Programas de Pós-Graduação em Artes Visuais; 6 Programas de Pós-Graduação em Educação; 6 Programas de Pós-Graduação em Comunicação e Semiótica. Estas e os demais Programas de Pós-Graduação podemos visualizar melhor no gráfico 2, segue abaixo: 
Gráfico 2 - Origem/quantidade de trabalhos por Programa de Pós-Graduação

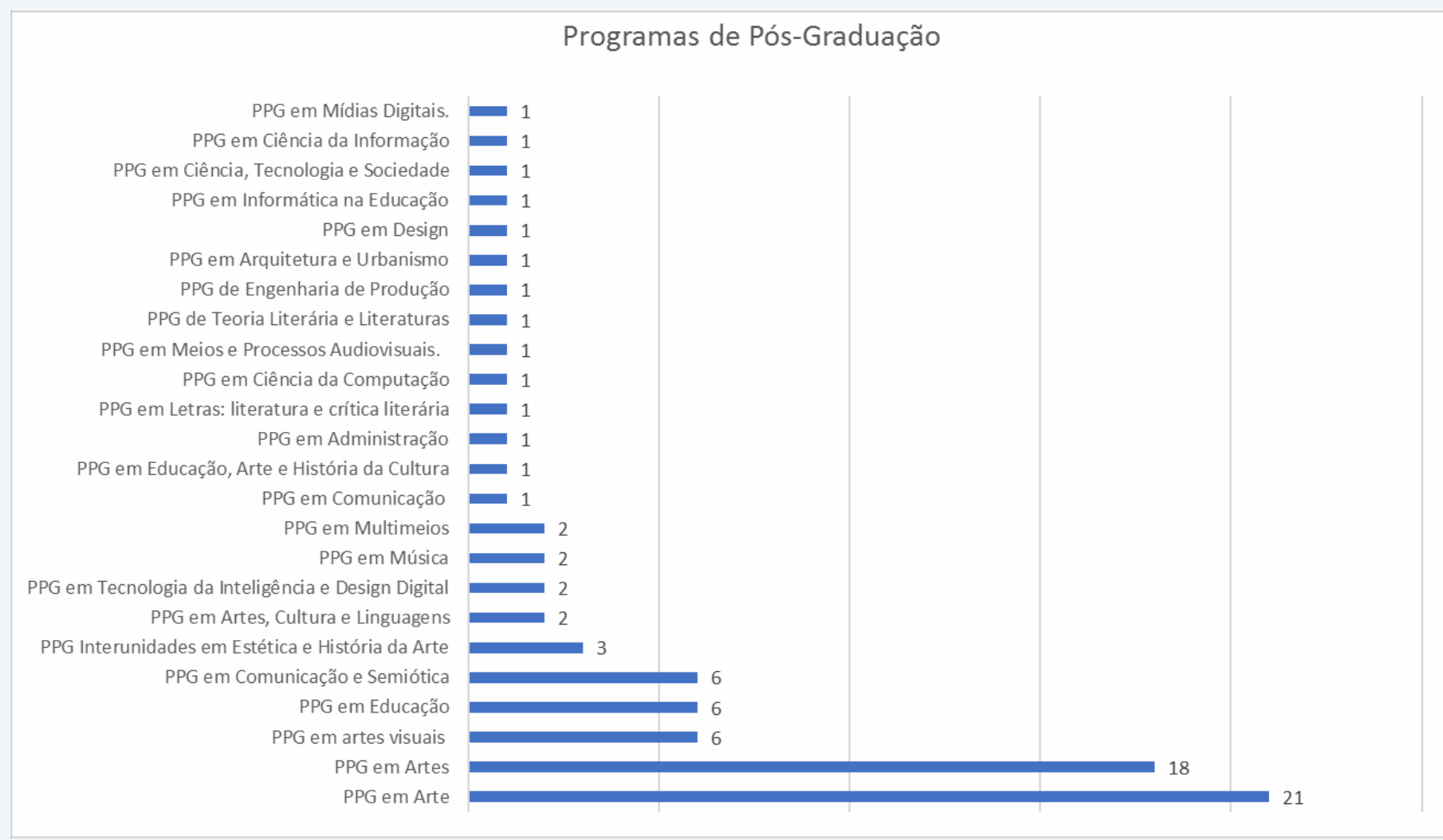

Fonte: Elaborado pelos autores (2020).

Quadro 1- Relação das Pesquisas (Teses e Dissertações) em ordem cronológica

\begin{tabular}{|l|c|c|c|c|c|c|c|c|c|c|c|c|c|c|c|c|c|}
\hline \multicolumn{1}{|c|}{ ANO } & 2002 & 2003 & 2004 & 2005 & 2006 & 2007 & 2008 & 2009 & 2010 & 2011 & 2012 & 2013 & 2014 & 2015 & 2016 & 2017 & 2018 \\
\hline TESES & - & - & 1 & - & & 1 & 1 & 2 & 1 & 4 & 4 & 1 & 4 & 3 & 1 & 2 & 1 \\
\hline DISSERTAÇÕES & 1 & 2 & 2 & - & 6 & 2 & 4 & 5 & 5 & 5 & 2 & 3 & 5 & 3 & 6 & 3 & 3 \\
\hline TOTAL & 1 & 2 & 3 & - & 6 & 3 & 5 & 7 & 6 & 9 & 6 & 4 & 9 & 6 & 7 & 5 & 4 \\
\hline
\end{tabular}

Fonte: Elaborado pelos autores (2020).

Para tanto, a descrição e categorização dos dados coletados segue os seguintes eixos/agrupamentos, com os respectivos autores/ano: A, B, C, D, E, F e G, que podemos verificar no quadro 3. 
Quadro 2 - Principais Abordagens: PPG em Educação, outros PPG com interfaces na arteeducação e outras temáticas registradas

\begin{tabular}{|c|c|c|c|c|c|c|}
\hline $\begin{array}{l}\text { A) PPG em } \\
\text { Educação }\end{array}$ & $\begin{array}{l}\text { B) Outros PPG } \\
\text { com interfaces } \\
\text { de arte e } \\
\text { educação }\end{array}$ & $\begin{array}{l}\text { C) Web museu, } \\
\text { seb arte, arte e } \\
\text { tecnologia }\end{array}$ & $\begin{array}{l}\text { D) Imagens e } \\
\text { produção } \\
\text { audiovisual }\end{array}$ & $\begin{array}{l}\text { E) Música e } \\
\text { cinema }\end{array}$ & $\begin{array}{l}\text { F) Games, jogos } \\
\text { arte e computado }\end{array}$ & $\begin{array}{l}\text { G) Ética, } \\
\text { poética e } \\
\text { estética }\end{array}$ \\
\hline $\begin{array}{l}\text { Bahia (2008) } \\
\text { Bedim (2011) } \\
\text { Hardagh (2009) } \\
\text { Andrade Junior } \\
\text { (2014) } \\
\text { Santos (2011) } \\
\text { Siqueira (2015) }\end{array}$ & $\begin{array}{l}\text { Loyola (2009) } \\
\text { Barcelos (2002) } \\
\text { Castro (2008) } \\
\text { Santos (2006) } \\
\text { Xavier (2013) } \\
\text { Campello (2013) } \\
\text { Salles (2014) } \\
\text { Sampaio-Ralha } \\
\text { (2003) } \\
\text { Costa (2011) } \\
\text { Ferreira Júnior } \\
\text { (2009) } \\
\text { Rosa (2004) }\end{array}$ & \begin{tabular}{|l} 
Allegretti (2018) \\
Amadeu (2006) \\
Baraúna (2016) \\
Bezerra (2007) \\
Blanco (2013) \\
Blumenschein (2008) \\
Boone (2013) \\
Costa (2018) \\
Cunha (2009) \\
Domingues (2008) \\
Gonring (2012) \\
Guimarães (2014) \\
Leonardo (2017) \\
Lima (2012) \\
Lin (2011) \\
Lucena (2010) \\
Mello (2015) \\
Miller (2006) \\
Neto (2010) \\
Noronha (2006) \\
Nunes (2003) \\
Oliveira (2010) \\
Padula (2007) \\
Silva (2014) \\
Praude (2015) \\
Pujatti (2017) \\
Fantini (2014) \\
Santos (2016) \\
Simas (2012) \\
Vasconcelos (2011) \\
Vieira (2016) \\
Weizmann (2006)
\end{tabular} & $\begin{array}{l}\text { Alves (2004) } \\
\text { Andrade (2007) } \\
\text { Santos (2011) } \\
\text { Barreiro (2015) } \\
\text { Bergantini (2016) } \\
\text { Higawa (2014) } \\
\text { Paula (2004) } \\
\text { Zanette (2017) } \\
\text { Henno (2016) } \\
\text { Thomazoni (2014) }\end{array}$ & $\begin{array}{l}\text { Almeida (2014) } \\
\text { Buck (2018) } \\
\text { Caetano (2015) } \\
\text { Barbosa Junior } \\
(2012) \\
\text { Monteiro (2012) } \\
\text { Rubini (2016) } \\
\text { Teles (2009) }\end{array}$ & \begin{tabular}{|l} 
Alves (2009) \\
Braga (2012) \\
Guimarães (2011) \\
Witt (2018) \\
Caetano (2010) \\
Silva (2014)
\end{tabular} & $\begin{array}{l}\text { Ferreira (2010) } \\
\text { Semeler (2011) } \\
\text { Silva (2017) } \\
\text { Bergamo (2008; } \\
\text { 2015) } \\
\text { Coelho (2009) } \\
\text { Paula (2017) } \\
\text { Pires (2016) } \\
\text { Barretto (2011) } \\
\text { Praude (2010) }\end{array}$ \\
\hline
\end{tabular}

Fonte: Elaborado pelos autores (2020).

Desse modo, na próxima seção realizamos as discussões e correlações entre os dados verificados, evidenciando as principais tendências das pesquisas.

\section{Apreciações e análises dos dados coletados}

Nesta seção, faremos algumas aproximações por eixos temáticos das pesquisas selecionadas e na sequência faremos entrelaçamentos com as respostas dos questionários dos professores que participaram dessa pesquisa, com as análises das dissertações de mestrado e teses de doutorado coletadas. Os resultados dos achados em dissertações e teses evidenciam seis (6) trabalhos discentes realizados em Programas de Pós-Graduação em Educação, dos quais encontramos: três (3) teses de doutorado e três (3) dissertações de mestrado. Uma (1) tese na 
Universidade Federal de Santa Catarina (BAHIA, 2008); uma (1) tese na Pontifícia Universidade Católica de São Paulo (HARDAGH, 2009); e uma (1) tese na Universidade de Brasília (SANTOS, 2011). Sobre as três (3) dissertações, identificamos uma (1) na Universidade Federal de São Carlos (SIQUEIRA, 2015); uma (1) na Universidade Estadual Paulista (BEDIM, 2011); e uma (1) na Universidade Estadual de Ponta Grossa (ANDRADE JUNIOR, 2014).

Identificamos também, em outros Programas, onze (11) trabalhos com interfaces da arte, tecnologia e educação, a saber: Duas (2) dissertações no Programa de Pós-Graduação em Artes, da Universidade Federal de Minas Gerais (LOYOLA, 2009; BARCELOS, 2002). Três (3) dissertações (CASTRO, 2008; SANTOS, 2006; XAVIER, 2013) e duas (2) teses (CAMPELLO, 2013; SALLES, 2014), na Universidade de Brasília, no Programa de PósGraduação em Arte. Uma (1) dissertação na Universidade Estadual Paulista, no Programa de Pós-Graduação em Arte (SAMPAIO-RALHA, 2003). Paralelamente, integramos uma (1) tese defendida no Programa de Pós-Graduação em Informática na Educação, da Universidade Federal do Rio Grande do Sul (COSTA, 2011); uma (1) dissertação no Programa de PósGraduação em Educação, Arte e História da Cultura, da Universidade de Brasília (FERREIRA JÚNIOR, 2009) e uma (1) tese no Programa de Pós-Graduação de Engenharia de Produção, da Universidade Federal de Santa Catarina (ROSA, 2004). Portanto, evidencia-se a relevância de dezessete (17) produções científicas para compor este trabalho. As demais pesquisas foram excluídas para o tratamento dessa investigação porque vão além dos objetivos propostos ou não englobam as questões validadas em experiências específicas de arte-educação-computador. Esse panorama foi dividido em duas grandes tendências para nortear as expectativas principais e os dados da literatura pesquisada, demonstrada em diversas pesquisas realizadas nos últimos tempos.

A primeira tendência foi designada por "Visitas de museus, cinemas, exposição de artes" e trata dos processos e experiências de arte desenvolvidas nas interfaces dos museus virtuais, exposição de arte e cinema digital (BAHIA, 2008; SIQUEIRA, 2015). Também se insere nesse conjunto multifacetado, o debate sobre o ensino em torno de questões, tais como, planejamento, estratégias, capacidades criadoras e conceitos geométricos no ensino fundamental, utilizando como pano de fundo a webquest "viajando nas obras de arte" (BEDIM, 2011) e o VJEdu, um software interativo para o visitante de uma exposição de arte (COSTA, 2011). Portanto, elencamos nesse delineamento quatro pesquisas integradas para o desenvolvimento potencial das artes por meio do digital, como uma arte presente e disponível 
às diversas vozes dos estudantes.

As possibilidades de experiências de exposições em museus, cinemas e exposições de artes pelo computador via conexão digital torna o saber acessível aos sujeitos e aos contextos escolares, desde que seja orientado pela relação da arte com a formação humana em espaços coletivos, conduzindo as pessoas para o (auto/re)conhecimento de leituras de mundos, cujas plataformas interativas auxiliam os professores em formas de aprendizagem híbridas (BAHIA, 2008). Cabe ressaltar que o acesso ao computador inspira ações e atividades que permitem o reconhecimento de culturas, de histórias de museus, exposição (exemplo da biblioteca à noite $)^{2}$ e a interdependência na organização dos materiais com trilhas de aprendizagem, investigações científicas e descobertas, conectando o local ao global. Ao evidenciar experiências de imersão em museus na posição de participantes, os professores, estudantes e escolas são conduzidos ao envolvimento com pesquisas em sites e em ambientes virtuais sensíveis, o que contribui para essas transformações sociais e culturais.

Para compreender melhor essa tendência na cultura da escola, os trabalhos elencados investigam como as escolas reconfiguram as práticas de artes e recontextualizam por meio da reelaboração dos processos educativos com a participação de ações digitais no cotidiano escolar. Assim, destacamos o potencial do cinema como uma arte contemporânea, atribuindo novas dinâmicas às construções históricas coletivas e relações entre os sujeitos, como forma de repensar os comportamentos cotidianos (BAHIA, 2008; SIQUEIRA, 2015). Desse modo, a arte nos abre um mundo de possibilidades que expande conversações e compreensões de mundo, uma vez que pode revelar os problemas existenciais concretos e as contradições vitais, favorecendo a compreensão dos fatos e os pontos de encontro entre os movimentos de renovação dos princípios pedagógicos que estruturam as áreas de conhecimento (BAHIA, 2008; SIQUEIRA, 2015; BEDIM, 2011; COSTA, 2011).

As experiências com as artes pelo computador criam ou reinventam outros pontos para a discussão, o que permite compartilhar novas combinações e aprofundamentos de relações e expressões de vida, além do valor de exposição, tornando os bens culturais acessíveis a todos. Possibilitar aos estudantes o acesso às artes pelo computador se constitui em uma alternativa interessante às diversas reflexões acerca da sociedade, da política, do preconceito, das incertezas e valores da vida em seus processos educativos (BAHIA, 2008; SIQUEIRA, 2015; BEDIM, 2011; COSTA, 2011). Assim, merece destaque a pesquisa da arte pelo computador de

\footnotetext{
${ }^{2} \mathrm{O}$ universo das grandes bibliotecas do mundo em realidade virtual pode ser visualizado em uma plataforma, no seguinte link: abibliotecaanoite.secrio.org.br
} 
Costa (2011), com o VJEdu - Video - Jockey educativo, que corresponde a um software com mediação de acesso ao público $e$ interativo para o visitante de uma exposição de arte, para ampliar os cruzamentos com a imagem, o som, o texto e a tecnologia. A acessibilidade ao acervo e à "documentação do centro de arte, da galeria ou do museu por vezes pode possibilitar uma pesquisa sobre o material de exposição corrente e mesmo das próximas exposições, o que possibilita ter um banco de dados potencialmente mais rico para o VJEdu" (COSTA, 2011, p. 118). Nessa dinâmica, as questões trazidas pela webquest "viajando nas obras de arte", apresentada por Bedim (2011), agregam experiências no ensino de conceitos geométricos no $2^{\circ}$ ano do Ensino Fundamental. Bedim (2011) parte da ideia de que a presença da Arte em nossas vidas pode ser contextualizada com a Matemática, a partir da Geometria, que está presente nas diferentes situações de diálogo e integração, "na natureza, nos objetos que usamos, nas artes, nas brincadeiras infantis, nos jogos, nas construções, etc. Ela faz parte da vida do ser humano desde a antiguidade, é um dos ramos mais antigos da Matemática, e estuda o espaço e as figuras que podem ocupá-lo" (BEDIM, 2011, p. 48). Por isso, Bedim (2011) indica que a Webquest enquanto metodologia para a pesquisa na escola pelo computador interconectado facilita a busca e tratamento das informações rastreadas, promovendo a motivação dos estudantes.

A segunda tendência está associada a "Experiências escolares de arte com o computador". As produções que compõem este grupo se constituem pelas diferentes experiências escolares de arte com o computador, conforme percebemos nas seguintes produções discentes. A pesquisa de Hardagh (2009) trata das redes sociais virtuais enquanto uma proposta de Escola Expandida; a arte digital e as narrativas sobre o processo criativo dos acadêmicos do Curso de Licenciatura em Artes Visuais - UEPG (ANDRADE JUNIOR, 2014); o ensino de arte e o computador em escola pública (LOYOLA, 2009); o uso do computador no ensino das Artes Visuais no Ensino Fundamental I (BARCELOS, 2002); da arte-educação e computador no Ensino Médio a partir da proposta triangular (SANTOS, 2006); as Escolas Parque de Brasília e o uso do laboratório de informática pelos educadores de arte (XAVIER, 2013); Arteduca e uma proposta de abordagem transdisciplinar para o ensino da arte em rede (CAMPELLO, 2013); os limites e possibilidades do uso de multimídias no ensino de arte no Município de Abaetetuba/Pará (FERREIRA JÚNIOR, 2009); a educação de educadores de arte e a construção de uma proposta de ensino multicultural a distância (ROSA, 2004); a rede social com música, arte e tecnologia (SALLES, 2014); as implicações da imagem digital para arte/educação contemporânea (CASTRO, 2008); e por fim, o uso da linguagem $\mathrm{VRML}^{3}$ na

\footnotetext{
${ }^{3}$ Sinteticamente, VRML - Virtual Reality Modeling Language é uma linguagem que permite descrever objetos 3D
} 
educação a distância em arte (SAMPAIO-RALHA, 2003).

A partir desse conjunto de pesquisas podemos identificar o papel do computador como um artefato de apoio ao professor em sala de aula em vista de suas características ágeis de busca, criação e divulgação da informação, sob o ponto de vista das relações entre arte, percepção e leitura da realidade, por meio da investigação artística e do reconhecimento dos processos no contexto cultural de produção da arte (SAMPAIO-RALHA, 2003; HARDAGH, 2009; ANDRADE JUNIOR, 2014; LOYOLA, 2009; BARCELOS, 2002; SANTOS, 2006; XAVIER, 2013; CAMPELLO, 2013; FERREIRA JÚNIOR, 2009; CASTRO, 2008).

Destaca-se que os desafios mencionados nessas produções consistem em incorporar o computador, mas sem simplificá-lo ou reduzi-lo aos procedimentos tradicionais de manipulação sem sentido ou de mera distração limitadora circunscritas aos instrumentos em si (limitação das práticas e dos materiais), no sentido de articulá-lo aos contextos de recriação que, nesse caso, é o componente definidor da experiência estética de concretização do ato criativo como apreciação, contextualização, historicidade e fazer artístico (SAMPAIO-RALHA, 2003; HARDAGH, 2009; ANDRADE JUNIOR, 2014; LOYOLA, 2009; BARCELOS, 2002; SANTOS, 2006; XAVIER, 2013; CAMPELLO, 2013; FERREIRA JÚNIOR, 2009).

Além disso, elencamos a tese de Santos (2011) que trata da arte-educação, adolescência e identidade tendo por base de referência os registros imagéticos. Parte da compreensão de que devemos levar em consideração as particularidades das escolas públicas de Ensino Médio, algumas com diversas carências, sobretudo emocionais pela falta de motivação (em realizar experiências de autoconfiança, empatia, autoestima e reconhecimento mútuo) dos estudantes na adolescência. Com base nessa tese identificamos a coautoria participativa via computador, para que todos saibam que são cidadãos ativos de um universo de reinvenções e de mundos. Tais práticas precisam sempre buscar construir novos olhares por meio de experiências que incentivem a cultura, o uso das linguagens (verbal, visual, gestual, musical, gráfica, reais ou imaginárias) e instiguem a reflexão com a realidade. Essas práticas possibilitam a autonomia, para lidar com as línguas, a pluralidade das mídias e as múltiplas práticas culturais de forma ética, estética, crítica e contextualizada (SANTOS, 2011).

Na tentativa de aprofundar alguns elementos nas produções sobre as quais é construída a ciência moderna, ressaltamos as características de reflexividade na comparação das seguintes temáticas: a formação e a discussão sobre a experiência artística, a sensibilidade na arte-

e agrupá-los através da construção de cenas ou verdadeiros mundos virtuais. Tais cenas são disponibilizadas na WWW e suas formas de aplicação são diversificadas, em áreas científicas, tecnológicas, de entretenimento e educação, passando por representações artísticas, multimídias e práticas transmídias. 
educação-computador e as experiências de arte-educação-computador nas escolas. Com os dados que coletamos, nos debruçamos agora em estabelecer entrelaçamentos das dissertações e teses com as experiências e percepções dos professores, a partir do questionário semiestruturado, que foi encaminhado a três professores ${ }^{4}$ que responderam e que atuam no campo das artes da Educação Básica, para o reconhecimento das experiências da arte e computador.

\section{Percepções dos professores e entrelaçamentos com as produções discentes}

A primeira questão - "O que você pensa a respeito do uso do computador na disciplina de Artes?” foi respondida por todos os participantes. A Professora $1^{5}$ respondeu que o computador representa "uma ferramenta de grande apoio e necessidade nos tempos atuais. Por exemplo, em aulas de artes pode facilitar o acesso a museus e espaços culturais que muitas vezes nossos alunos nem teriam conhecimento da existência". O Professor $2^{6}$, por sua vez, compreende que "o computador como fonte de pesquisa de imagens, vídeos, textos complementares na aula de Arte seria fundamental. Uma pena que nem sempre é possível o acesso ao laboratório de informática na escola (muitas não contam com laboratório ou internet aberta)". Já a Professora $3^{7}$ enxerga no “computador um recurso didático com muitas possibilidades pedagógicas de trabalho, além de dialogar com o cotidiano dos estudantes, é uma ferramenta com diversas potencialidades a serem exploradas no estudo de todas as áreas do conhecimento. Ressalto também a utilização dos ipads, tablets e celulares também como importantes aliados do ensino".

A partir das respostas dos professores sobre o que pensam do uso do computador nas aulas de Artes, foi possível notar que eles integram o computador aos processos de ensino e de aprendizagem do cotidiano escolar, como um recurso relevante para representar um conjunto de significados conceituais e práticas relacionadas com a produção e boa apreciação dos

\footnotetext{
${ }^{4}$ De acordo com a proposta inicial, tentamos contato com outros quatro professores, mas não obtivemos resposta porque já não trabalhavam nas instituições de ensino ou estavam sobrecarregados e se recusaram a participar ou a assinar o TCLE.

5 A Professora 1, formada em Artes Visuais pela Universidade Federal do Rio Grande do Sul (UFRGS), Especialidade em Poéticas Visuais pela FEEVALE. Atualmente, trabalha no município de Canoas/RS, na Escola Municipal Irmão Pedro.

${ }^{6}$ O Professor 2 formou-se na Universidade Luterana do Brasil (ULBRA) em Artes Plásticas, é pós-graduado em Arte-Educação pela UNIASSELVI. Atualmente, é professor no município de Porto Alegre na Escola Municipal de Ensino Médio e Fundamental Chico Mendes, no bairro Mário Quintana.

7 A Professora 3 é formada em Artes Visuais pela Universidade Federal do Rio Grande do Sul (UFRGS). Atualmente, trabalha no colégio Farroupilha, em Porto Alegre.
} 
estudantes. No contexto conturbado em que vivemos com o mundo digital, parece que esses professores conseguem experimentar processos de (re)criação nos quais tem o computador (um corpo inorgânico) como parceiro da experiência artística.

Nesse contexto, a dissertação de Loyola (2009) investiga as possibilidades do uso do computador e da web como meios de exploração pelos educadores nas atividades de ensino de Arte. O computador com conexão à internet foi se tornando progressivamente um artefato unificador de diversas mídias, diminuindo as fronteiras entre os suportes. Loyola (2009) afirma que a facilidade e a rapidez no acesso às informações e imagens podem propiciar uma relação diferente om os conhecimentos, de modo que o sujeito deixa de ser um elemento apenas passivo e passa a produzir e interagir com conteúdos na rede, capaz de gerar mudanças culturais e conceituais no uso da web. Assim, os professores de Arte precisam ficar atentos para as novas tecnologias que provocam novas sensibilidades e possibilidades aos estudantes, tendo em vista que a interação implica em experiências para a construção dos conhecimentos. Além disso, o uso do computador possibilita a construção artística provocadas, em parte, por softwares de desenho, de edição de imagens e outros usos da web, cujas variações das artes e dos diferentes processos artísticos desvelam a apreciação de obras de arte e diversas versões digitais e virtualizadas em sites e museus de arte.

Soma-se a essa abordagem, a dissertação de Barcelos (2002) que apresenta a questão do uso do computador no Ensino Fundamental I, com crianças de oito a dez anos de idade, a partir da perspectiva de que pensar a arte é um processo criativo que tem interação com a sensibilidade, sendo ambas potencialidades humanas. $\mathrm{O}$ uso do computador no trabalho com artes visuais abre diversas possibilidades para a educação nas questões artísticas e estéticas da produção do conhecimento, para pensar o tempo, o movimento, a cor, a imagem, o som, além de possibilitar debates interdisciplinares ligados ao mundo imagético das telas. Barcelos (2002) reitera que o uso do computador na escola, enquanto possibilidade de se pensar e fazer arte, desvela ao olhar um mundo em que a visão é bombardeada por imagens, lembranças, associações, interpretações e fantasias de um passado do mundo em realidade virtual.

Entre diálogos e contextos diversos, Castro (2008) traz em sua dissertação que as imagens digitais se constituem parte de uma linguagem distribuída no ciberespaço e as interconexões gráficas associam esse escopo e possuem função de destaque nas interações entre usuário e máquina, entre usuário e usuário. Desse modo, Castro (2008) questiona em sua investigação o que muda na prática pedagógica com a introdução das tecnologias de informação e comunicação no contexto educacional, interessando-se pelas implicações da imagem digital 
para a arte/educação contemporânea. O conjunto de aparelhos digitais oferecido pelas tecnologias em resposta a uma arte eletrônica digital facilita o acesso às produções e a difusão de imagens pois, até então, a produção e as regras do diálogo estavam dependentes dos sistemas analógicos. Sendo assim, por intermédio das tecnologias amplia-se o horizonte das artes visuais e seu ensino se expande com a arte/educação de hoje, levando a uma ação crítica e enunciadora das aulas e dos processos de mudança, sendo inspiradora à produção de imagens/metamorfoses.

A segunda questão investiga com os professores se os métodos tradicionais de ensino das Artes foram ressignificados com o computador, e como eles poderiam exemplificar tais mudanças na prática pedagógica. A Professora 1 afirma que:

\begin{abstract}
Atualmente a tecnologia está presente em computadores, smartfones, tablets entre outras ferramentas e meios digitais. Sua funcionalidade e aplicabilidade em sala de aula se torna cada vez mais frequente e interessante, permitindo ampliar o interesse e participação dos alunos nas aulas. Um exemplo prático bastante comum hoje em dia é o uso de ferramentas do Google for Education, como por exemplo a ferramenta Google sala de aula, que permite você desenvolver aulas invertidas, fóruns, atividades e trabalhos por meio digital, reforçando o que foi trabalhado na sala de aula.
\end{abstract}

Como podemos perceber, complementa a argumentação da Professora 1, a perspectiva de Sampaio-Ralha (2003), que propõe, em sua dissertação, o estudo da arte através do suporte trazido pelo computador em rede, com a utilização das tecnologias de simulação de Realidade Virtual. Avalia o uso de linguagem VRML enquanto caminho para a criação de ambientes virtuais, apontando algumas características da arte, dentre elas, a percepção da tridimensionalidade, agrupando os principais resultados alcançados em pesquisas sobre o uso do VRML e sua aplicabilidade para a construção do conhecimento em Arte. A proposta tem em sua aplicação o desenvolvimento de conceitos no estudo das artes com a finalidade de possibilitar a aprendizagem em arte na virtualidade da comunicação (a distância), a partir das experiências de envolvimento sensorial e apreciação artística possíveis com a Realidade Virtual. A autora usa a linguagem VRML para realizar a simulação e reproduzir obras visuais nos ambientes virtuais. Sampaio-Ralha (2003) salienta que a iniciativa não tem a finalidade de substituir os professores e tutores nos processos de ensino, mas de viabilizar o acesso de conteúdos de formas diferenciadas para um número maior de sujeitos, por meio das possibilidades não presenciais e assíncronas de aprendizagem, pelas redes de computadores interligados a distância, via e-Learning .

A dissertação de Ferreira Júnior (2009) também dialoga com essa perspectiva, ao discutir uma problemática que os estudantes ribeirinhos do Ensino Modular de Abaetetuba, no 
Estado do Pará, têm enfrentado nas práticas pedagógicas em Artes em relação à pauperidade de estrutura física e inadequação tecnológica. Diante disso, investiga os limites e possibilidades em produzir com os educandos ribeirinhos uma experiência estética virtual, por meio de pesquisas nos recursos multimídias, principalmente a internet, com o recorte do Patrimônio Cultural do Pará. Com o objetivo de analisar se esses artefatos tecnológicos podem ajudar os sujeitos a receberem um ganho qualitativo para a construção do conhecimento em arte, Ferreira Junior (2009) efetivou uma pesquisa de intervenção participativa, de tipo analítico descritiva, no contexto de duas escolas municipais localizadas no Município de Abaetetuba, envolvendo estudantes de oitavo ano do Ensino Fundamental e do primeiro ano do Ensino Médio. O estudo aponta que as aulas de arte se mostram mais provocadoras e instigantes, sob a perspectiva dos estudantes, quando alicerçadas em propostas pedagógicas oriundas das tecnologias aliadas aos processos de ensino e de aprendizagem.

Essa perspectiva permite repensar o conhecimento presente na resposta do professor 2: "Antigamente haviam poucas referências visuais juntamente com o cinema e TV, hoje, os alunos são bombardeados por referências visuais em jogos, filmes, séries, HQs, animações e aplicativos". No contexto contemporâneo, "o professor sabendo que a bagagem visual dos alunos hoje é muito variada e extensa pode aproveitar e usar tudo isso em aula". A tese de Bahia (2008) corrobora desse reconhecimento, ao tratar de questões associadas aos jogos online lançados pelo setor educativo de museus de arte, de obras dos acervos. Entre os anos de 2005 e 2008, a autora realizou uma pesquisa de campo na Web, na perspectiva de selecionar, estudar e interagir com as interfaces da temática, analisando ainda sites informativos no campo das Artes. Concluiu que a interface do jogo online se mostra coerente com a recente teorização acerca de Museus, tomando por base autores como Martín-Barbero e Hooper-Greenhill, Gadamer e Barthes, para pensar a temática das obras de arte. Tal abordagem é capaz de deslocar o visitante de um museu da posição de espectador para participante, ou seja, leva o sujeito para a experiência de imersão que vai além da pura contemplação, excedendo o sentido visual à tatilidade característica da interatividade. Bahia (2008) afirma que a curiosidade por conhecer novos modos da arte na Web conduziu para o desvelamento de novos modos de sentir a vida em direção ao outro, caracterizado pela diferença, assegurando assim, novas interfaces computacionais, tanto na questão da inovação quanto na sua retroação, na atualização das tradições. É nesse sentido que,

A cibercultura germinou não apenas pelo advento Remate 380 do PC e da Web, mas porque ruiu o muro que um dia tentou separar saber vivido e acadêmico, mundo jovem e adulto, riso e seriedade, trabalho e lazer, cultura 
cotidiana e erudição, Mídia e Arte, Eu e Outro, sabor e saber. (BAHIA, 2008, p. 380).

Nessa abordagem podemos elencar também a tese de Campello (2013), que traz uma contribuição para o campo da educação a distância em arte e tecnologia, resultante da apresentação de uma proposta metodológica, a partir do planejamento e oferta do curso de especialização Arteduca: arte, educação e tecnologias contemporâneas. É nesse espírito que remonta à proposta de problematização, o desocultar e perceber as relações entre o que se estuda e seu contexto aprendente, a mediação e a colaboração da teoria dialógica de Paulo Freire recebe grande sentido quando busca conhecer o contexto em que atua, para projetar ações interdisciplinares, como no caso da Arteduca. Assim, a investigação precisa ser baseada em temas geradores de aprendizagem ou de uma temática significativa para o contexto das ações pedagógicas. Já a Professora 3 entende da seguinte forma a pergunta - se os métodos tradicionais de ensino das Artes foram ressignificados com o computador:

Acredito que sim. O uso da tecnologia ultrapassou a simples projeção de um PPT. Muitos são os programas de edição de imagem, tours virtuais em museus, galerias e espaços culturais, páginas de artistas e espaços de arte que oferecem um percurso didático que alimenta o repertório cultural, imagético, estético e visual dos estudantes. A videoarte, a fotografia, as instalações e o hibridismo presente na arte contemporânea prova que a tecnologia é também um meio de expressão e uma linguagem artística.

Assim como a Professora 3, podemos articular sua percepção com os dados trazidos pela tese de Santos (2011), que integra os significados da produção visual dos estudantes de Ensino Médio, tendo como lócus investigativo uma escola pública. A tese atravessa as vivências e discussões dos adolescentes, como forma de preservação das possibilidades de futuro na formação da própria identidade da adolescência, na ocorrência e interferência das mídias estruturais que normalizam a cultura, bem como a construção da identidade dos adolescentes e os valores sociais das produções trabalhadas em aulas de Artes Visuais. Santos (2011, p. 315) percebe que os modos de articulação e os atravessamentos da educação é permeado pelos novos meios de comunicação e pelos gêneros textuais (computacionais), que produz ideologias e formas de poder, sendo indicador da urgência em fazer uma revisão da produção dos sentidos da multimodalidade comunicacional, uma vez que das "intenções comunicacionais emanam atitudes que dialogam com a (a)firmação da identidade". Santos (2011, p. 315) corrobora que no cotidiano dos adolescentes, a imagem sempre se faz presente e as oportunidades de se trabalhar com a imagem, "não como ilustração, mas como evidência de construção de um processo que se valeu da análise, produção, interpretação e fruição, puderam contribuir para 
(re)pensar a importância e ocorrência da imagem no ensino-aprendizagem das Artes Visuais". Tal análise justifica que "a imagem faz parte de uma complexa construção coletiva que engendra a identidade (pessoal e social) e a produção de sentidos coletivos - e produção coletiva de sentidos" (SANTOS, 2011, p. 315).

Acrescenta-se ao debate, a dissertação de Siqueira $(2015$, p. 6) desenvolvida e vinculada a "um recorte sobre a estereoscopia, que produz o efeito de profundidade no cinema 3D e o uso das CGI (Computer generated imagery)", que se compõe por imagens animadas de modo digital, cujo objetivo é questionar os impactos sobre a experiência do espectador na interação com as obras cinematográficas. Investiga as novas particularidades do cinema digital com o intuito de compreender as modificações na linguagem do cinema e nos conteúdos abordados, reconhecendo as características nos modos de percepção que nascem do cenário da cultura audiovisual digital do século XXI. A autora afirma que as novas tecnologias utilizadas no cinema digital e na própria linguagem cinematográfica estão em contínua transformação, assim como as técnicas atinentes ao cinema digital acabam transformando o modo como o espectador interage com o filme. Com isso, a responsabilidade social aumenta ainda mais com o uso dos recursos digitais de CGI e 3D, pois eles fornecem diversas possibilidades criativas, mas também são utilizados, em muitos casos, para não trazer ganhos significativos para a experiência do espectador quando incutem elementos que apenas confirmam e conformam a reprodução de um maior realismo às imagens. Contudo, Siqueira (2015, p. 137) contrapõe a essa ideia uma outra, indicando que existem "artistas preocupados em usar tais recursos não para conferir maior realismo às imagens, mas como mais um recurso da linguagem cinematográfica, que têm seus limites criativos expandidos, permitindo que surjam novas experiências por meio do cinema". Daí precisamos pensar e se manifestar quanto à educação no campo das artes calcada na reprodução de questões técnicas, metodológicas, que afastam as experiências humanas do contato com as diferentes linguagens e com as discussões políticas e sociais.

A terceira questão perguntava se as mudanças com o acesso ao computador na escola onde atua influenciava a aprendizagem do educando na leitura crítica e no desenvolvimento do olhar sensível e inventivo/imaginativo, tendo em vista os estímulos visuais da atualidade. A Professora 1 assumiu a seguinte posição: "Com certeza! Nossos alunos se mostram mais interessados, buscando outros olhares e opiniões sobre o que é debatido", tendo em vista que "participam mais das propostas das aulas e até dão seguimento aos estudos por casa como o uso da metodologia de aula invertida". O Professor 2 respondeu que "a maior mudança está na 
forma que o aluno consome e reproduz as informações que recebe”. A Professora 3, por sua vez, afirmou:

Com certeza. Além das aulas voltadas especificamente para o pensamento computacional, a integração da tecnologia nos demais campos do saber vem a agregar no desenvolvimento das variadas habilidades propostas. No entanto, destaco que se usada de forma tradicional, o ensino seguirá o mesmo mudando apenas o seu meio de acesso ao estudante. O simples fato de ter um computador em sala de aula não quer dizer que se está desenvolvendo uma proposta que possibilite o estudante a experienciar e experimentar as possibilidades criativas disponibilizadas pela tecnologia. Para isso, é de suma importância a atualização do professor diante da profusão de ferramentas disponíveis na atualidade para, de fato, contribuir e gerar um ambiente propício para o desenvolvimento de uma leitura crítica do nosso entorno no meio desse turbilhão imagético ao qual estamos inseridos.

Essa análise dos reais significados e representatividade alcançada pelo olhar crítico sobre as tecnologias na própria realidade realizado pela Professora 3 converge com a tese de Hardagh (2009) que apresenta a concepção das redes sociais e Web 2.0, levantando suas características e seu potencial enquanto espaço de aprendizagem como escola expandida, ancorada na teoria de Vygotsky, Bakhtin e Lucia Santaella. Tais autores têm em comum a valorização da relação dialógica enquanto espaço para construção de conhecimento e a importância da linguagem na construção social, cultural e histórica dos sujeitos.

Hardagh (2009) busca inspiração na arte para propor aos educadores o movimento de se aventurarem na criação de estratégias para a transformação da prática pedagógica envolvendo o currículo, o espaço e tempo da escola. Para a pesquisa, a autora utiliza dados coletados de maio de 2007 a março de 2008, por meio de depoimentos espontâneos e da aplicação de um questionário para os estudantes que participaram de grupos focais formados pelos cursos de Design de Moda, Tecnólogo de Produção de Multimídia e Bacharel de Comunicação Visual, no Centro Universitário SENAC. Hardagh (2009) compreende que os estudantes conferiram sentidos às redes sociais e Web 2.0 enquanto ambientes para a sociabilidade e compartilhamento de informações e posturas colaborativas, voltadas também para a cooperação e a produção de saberes. A partir dos depoimentos, verifica "que a maioria dos ciberjovens valoriza as formas tradicionais de educação e entende a necessidade de somar o potencial da tecnologia às práticas educacionais", entendida como oportunidade para reunir recursos, ratificando a proposta de Escola Expandida (HARDAGH, 2009, p. 6).

A quarta questão indagava por que ainda é pouco explorado o uso do computador associado às Artes. A Professora 1 assim respondeu: 
Creio que o computador é uma ferramenta de apoio, assim como um livro, um filme ou até mesmo slides. O computador, talvez ainda seja pouco usado no caso de escolas que não possuem este recurso ou dependa de agendamentos que se prolongam na reserva de datas. No meu caso, que trabalho em escola pública, nosso laboratório é bem precário, mas os celulares ajudam bastante nessa hora, para casos de consultas, pesquisas ou acessos rápidos. Iniciaremos o trabalho com os chromebooks, o que com certeza melhorará em muito a prática dos educadores com relação as tecnologias digitais.

$\mathrm{Na}$ tentativa de interpretar essa questão com as produções garimpadas, destacamos a tese de Rosa (2004), que desenvolveu uma proposta de educação permanente de professores de arte. A proposta instigou a produção de um conjunto de ações e conhecimentos via ambiente virtual, que possibilitou aos professores o compartilhamento de um processo de educação a distância, auxiliando para a expansão dos usos das tecnologias da imagem móvel, do computador e da internet, no cenário educacional. Uma perspectiva educacional multicultural congrega práticas pedagógicas que levam em consideração as questões sociais, étnicas, culturais, de gênero, políticas, assim como possibilita não apenas o acesso, mas o conhecimento em outras abordagens, além das divulgadas pela arte institucionalizada, que são predominantemente constituída por conceitos europeizados. Rosa (2014) aponta que no contexto escolar percebe-se que os computadores que chegam para os professores estão se tornando cada vez mais próximos e que aos poucos os professores estão desenvolvendo críticas, podendo extrair notórios benefícios com o acesso e a exploração desses recursos para qualificar as ações e os espaços de expressividade. Embora muitas instituições de ensino façam uso de computadores para capacitar os professores, como é o caso da rede pública municipal de Florianópolis, a autora reconhece que mesmo onde já acontecem experiências do uso do computador, há uma tendência em subutilizar esses instrumentos em relação às potencialidades criativas das artes.

O Professor 2 revela como resposta à quarta questão que "muitas escolas não dispõem de um laboratório e em alguns casos existe uma combinação de uso com outras disciplinas (o professor deve reservar num setor da escola e depende também se o equipamento está em boas condições)". Nesse ponto, vale mencionar a dissertação de Xavier (2013) que apresenta a conjuntura do uso dos laboratórios de informática em Escolas Parque de Brasília, a partir do Programa de Informatização das Escolas Públicas do Governo Federal, que é responsável pela distribuição e instalação de laboratórios de informática nas escolas públicas brasileiras. Analisa que as políticas públicas de promoção do acesso e capacitação ao uso das tecnologias para renovar as práticas educacionais e sociais. Xavier (2013, p. 112) destaca que "mais da metade dos professores declararam estar entre pouco ou nada capacitados para o uso do laboratório de 
informática sem a presença de um professor responsável pelo ambiente". Contudo, "muitos professores têm interesse na formação continuada, entretanto não existem cursos diferenciados, com perfil para professores da Escola Parque, oferecidos na EAPE (NTE PP/C)”, mas, a falta de vagas para os cursos oferecidos não supre a demanda dos interessados, gerando desmotivação nos professores (XAVIER, 2013, p. 112).

Vejamos também a tese de Salles (2014) que defende a necessidade de repensar os modos de aprendizagem com a argumentação que suas inquietações surgem a partir do retorno da obrigatoriedade do ensino de música nas escolas e das experiências pedagógicas para o ensino de teclado em grupo mediado pelas tecnologias. Isso significa assumir o aprender a apreender diante dos novos desafios tecnológicos, para criar condições de ambientes interativos musicais de perspectivas não apenas multidisciplinar, mas também transdisciplinar, que seja capaz de estabelecer um entrecruzamento de sentido contraditório "entre uma variedade de teorias, modelos, técnicas e ferramentas das áreas de Computação Musical, Educação Musical, Interação Humano-computador e Inteligência Artificial, dentre outros" (SALLES, 2014, p. 6). O produto e objeto da investigação de Salles (2014), a rede social \#musicanaescola, pretendeu fomentar o processo de ensino musical com o uso das tecnologias, compartilhando experiências educativas do fazer musical, de modo que os processos e práticas musicais nas escolas emerjam dos contextos locais para contextos globais. Vale destacar, ainda, as pesquisas de Rocha e Baranauskas (2000, p. 7), cujas investigações apontam:

A comunidade profissional interessada na interação humano computador data do início da década de 80 , época em que os computadores pessoais começaram a ganhar mercado e escapar ao uso restrito de especialistas. O desenvolvimento da área nas últimas duas décadas gerou um corpo de conhecimentos que tem ganhado espaço dia a dia junto à indústria de software. Exemplo disso são os laboratórios de usabilidade de software e departamentos especiais em design criados nas grandes fabricantes de software como é o caso da Xerox, Apple, etc. Interação Humano-Computador (IHC) pode ser definida como a disciplina relativa ao design, avaliação e implementação de sistemas computacionais interativos para uso humano e aos fenômenos que os cercam.

A Professora 3 afirma que o computador é pouco explorado nas salas de aula, o que não acontece pelos artistas, pois eles utilizam muito o computador. Em suas palavras, "a justificativa poderia recair sobre a falta de domínio dessa ferramenta por parte de muitos educadores, uma vez que sua inserção em sala de aula ainda é recente na maioria das escolas. Políticas de formação continuada nessa área seriam bem vindas”. Nesse ponto, elencamos a dissertação de Santos (2006) que tem em vista a necessidade de um aprofundamento em relação ao uso das tecnologias nos processos de ensino e aprendizagem em Artes Visuais nas escolas públicas de 
Ensino Médio do Distrito Federal. A Proposta Triangular de Ana Mae Barbosa é o horizonte de entendimento para a construção das práticas pedagógicas dialógicas, contextualizadas e hipertextuais, conforme o autor. Santos (2006) também aponta para a necessidade de promover reflexões em torno das competências, capacidades e habilidades que são desenvolvidas com as aproximações dos repertórios em torno da cultura visual, propiciando a autonomia, o desenvolvimento do senso reflexivo e crítico dos sujeitos.

A quinta questão investigou quais seriam as vantagens e desvantagens do uso do computador nas aulas. A Professora 1 descreveu "como vantagens as possibilidades de consultas online, busca por obras e biografia de artistas, jogos e leituras sobre arte e possibilidades envolventes para os alunos”. A dissertação de Bedim (2011) se insurge nesse cenário ao tratar das contribuições da Webquest Viajando nas Obras de Arte no ensino de formas geométricas para crianças do $2^{\circ}$ ano do Ensino Fundamental. De acordo com a autora, a Webquest Viajando nas obras de Arte "não propiciou que a criança dessa faixa etária vivenciasse os quatro processos que devem estar presentes e articulados no ensino de Geometria, a saber: percepção, construção, representação e concepção", mas foi possível trabalhar a percepção, a visualização das formas geométricas, mas carecendo da construção e representação dessas formas (BEDIM, 2011, p. 9). O contexto de investigação permitiu inferir que "a articulação de outras atividades com a Webquest levou os alunos a progredirem nos níveis de van Hiele de pensamento geométrico, do nível básico, no qual o espaço é somente observado, para o nível um, em que começam a discernir sobre as características das figuras" (BEDIM, 2011, p. 9). Em relação às desvantagens, a Professora 1 fez a seguinte afirmação:

Vejo como desvantagens as limitações que algumas escolas possuem em equipamentos técnicos (computadores antigos ou limitados em capacidade), também percebo que estamos vivendo essa transição do abandono do livro impresso e caderno como únicas ferramentas de aprendizagem, o que faz com que nosso aluno esteja aprendendo a trabalhar com essa nova ferramenta para uso pedagógico e não apenas de entretenimento ou lazer.

Já o Professor 2 faz a seguinte afirmação: "Só vejo vantagens como o uso de imagens em grande escala quando usado um telão/projetor, vídeos, visitas virtuais aos maiores museus de outros países, pesquisa de materiais/técnicas/artistas/obras". A partir dessas compreensões, observamos que os professores entendem que a disseminação da tecnologia digital é praticamente uma realidade no campo da educação artística. Nesse ponto, inspirada na cultura de Video-Jockey de edição ao vivo de imagens e música, a tese de Costa (2011) trata das mídias digitais que possuem diferentes linguagens para seu uso, ampliando a experiência das pessoas que visitam exposições de arte. Segundo o autor, a pesquisa partiu da necessidade de elaboração 
de uma tecnologia específica para galerias e museus de arte, abrangendo a adequação de um software, criando novas funcionalidades de interação com a base de dados composta por vídeo, som além das mídias de imagem e texto. Desse modo, Costa (2011, p. 6) revela uma possibilidade de uso do software nas "galerias, museus, outras instituições culturais e educacionais, bem como nos setores de mediação educativa em mostras como as Bienais de Arte”. Essa abordagem também se associa ao que a Professora 3 argumentou:

Não vejo desvantagens se a proposta de trabalho considerar a segurança digital do estudante diante de páginas da internet que não configuram sua faixa etária. Vejo o computador, assim como outros dispositivos eletrônicos, como aliados na fazer pedagógico, conversando também com as demais formas de comunicação. As habilidades do fazer manual, do contato com materiais, técnicas e procedimentos artísticos diversos não devem ser extintos, apenas dividir espaço com a tecnologia que já está inserida no dia a dia (de muitos) dos estudantes, mas pouco em sala de aula. Acrescento não só dividir espaço, mas compartilhar práticas de ensino híbrido.

Essa proximidade de raciocínio também é compartilhada por Andrade Júnior (2014) que busca identificar em sua dissertação as prioridades dos acadêmicos de licenciatura do terceiro ano do Curso de Artes Visuais da UEPG, para o processo de aprendizagem e criação artística via computador. Deste processo emergiram "categorias de análise e as divisões das etapas dos estudos que proporcionaram constatações sobre os conceitos de Arte Digital, Poéticas Digitais, além das prioridades dos sujeitos no processo de aprendizagem e criação artística digital" (ANDRADE JÚNIOR, 2014, p. 9). Os posicionamentos e expressões a partir de concepção das obras digitais têm contribuído para a perspectiva da "práxis criadora digital", ou seja, para uma leitura mais aprofundada dos acadêmicos nas interatividades com o computador elaboradas na aprendizagem e criação de Arte digital (ANDRADE JÚNIOR, 2014).

Ao fechar essa seção, destacamos que a tarefa de desmistificar a tríade arte-educaçãocomputador na cultura escolar e fazer dialogar a ciência com a arte no cotidiano exige o questionamento dos pilares conservadores das tecnologias assentados na ideia de um computador controlador (operacional e de softwares complexos), inviável e custoso para a educação (HABOWSKI, 2019). Na prática educativa, ainda que se tenha como esforço o uso do computador, pouco sabemos na prática pedagógica ao certo para que o computador serve, sendo tomado, muitas vezes, de forma equivocada no plano repetitivo (da produção de mercadoria) e técnico de um exercício padronizado.

\section{Reflexões finais}

A investigação perpassou a compreensão das percepções educacionais mediadas pelo 
computador, como forma de conjugar a interpretação de contextos culturais com o diagnóstico do momento vivido atrelado aos repertórios escolares, discutindo os desafios de "uma mediação crítica do universo da arte na educação, enquanto gesto reflexivo, intercâmbio dialógico e emancipatório, ao mesmo tempo possível e bloqueado pelas relações opostas e intensas da atualidade" (CONTE; DEVECHI, 2016, p. 1216). A percepção dos professores que atuam no campo apresenta e recorda assuntos pertinentes para resgatar uma pedagogia dialógica e transformadora com os recursos audiovisuais presentes no cotidiano escolar, identificando assim os motivos pelos quais ainda há resistência a desenvolver aulas de artes com computadores. Assim, dialogar sobre arte-educação e computador nos processos educativos coloca em movimento as instâncias formativas e os potenciais adormecidos e ainda inalcançado na escola, pois provoca e convoca as esferas interdisciplinares de diferentes campos, abrindo possibilidades para explorar o expressivismo no universo das tecno-imagens, como o mundo da técnica imaginativa e da livre-expressão sensível e emotiva (FLUSSER, 2012). Para que as produções gráficas façam sentido para os estudantes, é fundamental considerar o tempo, o espaço e o processo das atividades, explorando as múltiplas linguagens e as diversas capacidades de imaginação, oportunizando ao educando criar, experimentar os existenciais, exprimir o que sente, sendo imprescindível o desenvolvimento da afetividade e da sensibilidade, que passa pelo olhar do professor diante do arsenal tecnológica disponível (SALLES, 2014; SAMPAIO-RALHA, 2003; BARCELOS, 2002; BEDIM, 2011; COSTA, 2011).

O fato é que as formas de uso do computador precisam ser reinventadas porque desencadeiam reflexos diretos no cotidiano escolar e social, sendo a comunicação e o compartilhamento de informações características essenciais dessa nova realidade, que admite conexões a distância entre os atores sociais, revertendo os problemas ocasionados pela fragmentação de investigações e práticas, e justificando os benefícios disponibilizados pelas tecnologias digitais enquanto processos reflexivos, criativos e de construção do conhecimento nas escolas (BULHÕES, 2010; SAMPAIO-RALHA, 2003; ROSA, 2004). Na verdade, o computador interconectado inclui narrativas estéticas e o reconhecimento de diferentes histórias e formatos (filmes, vídeos, etc.), viabilizando uma linguagem movente que inclui imagem, som, movimento e atuação em tempo real, tornando as aulas dinâmicas e surpreendentes quando incentivadas dentro dos processos de construção de conhecimentos em artes e práticas transmídias. Isso tudo nos remete ao fato de que "por meio da arte, os sujeitos da educação ampliariam a sua capacidade de reflexão e percepção crítica da realidade, assim como sua sensibilidade no processo de humanização" (CONTE; DEVECHI, 2016, p. 1220). 


\section{REFERÊNCIAS}

ANDRADE JÚNIOR, Anselmo Rodrigues de. Conheço, entendo, logo crio: arte digital e as narrativas sobre o processo criativo dos acadêmicos do curso de licenciatura em artes visuais - UEPG. 2014. 226f. Dissertação (Mestrado em Educação) - Universidade Estadual de Ponta Grossa, Ponta Grossa, 2014.

ARAUJO, Joao Paulo Ferraro Turano de. Experience and Nature: Contribuições para o fazer-pensar educacional do século XXI. 2018. 94 f. Dissertação (Mestrado em Educação) Pontifícia Universidade Católica do Rio de Janeiro, Rio de Janeiro, 2018.

BAHIA, Ana Beatriz. Jogando arte na Web: educação em museus virtuais. 2008. 401f. Tese (Doutorado em Educação) - Universidade Federal de Santa Catarina, Florianópolis, 2008.

BARCELOS, Fátima Pinheiro de. O uso das tecnologias informatizadas no Ensino fundamental I: o uso do computador no ensino das artes visuais. 2002. 125f. Dissertação (Mestrado em Artes) - Universidade Federal de Minas Gerais, Belo Horizonte, 2002.

BEDIM, Acácia Aparecida Pinto. O ensino de conceitos geométricos no $2^{\circ}$ ano do Ensino Fundamental usando a Webquest Viajando nas Obras de Arte. 2011. 174f. Dissertação (Mestrado em Educação) - Universidade Estadual Paulista, Presidente Prudente, 2011.

BOAS, Valeria de Alvarenga Pimenta Vilas. A professora e o uso do computador na alfabetização. 2014. 196 f. Dissertação (Mestrado Profissional em Educação) - Universidade Federal de Lavras, Lavras, 2014.

BULHÕES, Maria Amelia. Transterritórios: campo da arte e internet. Visualidades, Goiânia, v. 8, p. 11-22, 2010.

CAMPELLO, Sheila Maria Conde Rocha. Arteduca: uma abordagem transdisciplinar para o ensino da arte em rede. 2013. 313f. Tese (Doutorado em Arte) - Universidade de Brasília, Brasília, 2013.

CASTRO, Rosana Andréa Costa de. Tecnologias de Informação e Comunicação: implicações da imagem digital para arte/educação contemporânea. 2008. 106f. Dissertação (Mestrado em Arte) - Universidade de Brasília, Brasília, 2008.

CONTE, Elaine; DEVECHI, Catia Piccolo Viero. A experiência estética em tempos de virtualização tecnológica. Cadernos de Pesquisa, São Paulo, v. 46, p. 1216-1233, 2016. DOI: https://doi.org/10.1590/198053143724

CONTE, Elaine; MARTINI, Rosa Maria Filippozzi. Fenomenologia e Hermenêutica: um desafio para a educação? Veritas, Porto Alegre, v. 64, p. 28372-28, 2019. DOI: https://doi.org/10.15448/1984-6746.2019.2.28372

COSTA, Júlio Caetano. Vjedu - vídeo-jockey educativo: um software interativo para o visitante de uma exposição de arte. 2011. 126f. Tese (Doutorado em Informática na Educação) - Universidade Federal do Rio Grande do Sul, Porto Alegre, 2011.

FERREIRA JÚNIOR, Angelino Gomes. Os limites e possibilidades do emprego de 
multimídias no ensino de arte no Município de Abaetetuba/Pará. 2009. 118f. Dissertação (Mestrado em Educação, Arte e História da Cultura) - Universidade Presbiteriana Mackenzie, São Paulo, 2009.

FLUSSER, Vilém. O Universo das imagens técnicas. Elogio da superficialidade. Coimbra: Annablume, 2012.

GADAMER, Hans-Georg. Verdade e método. 7. ed. Petrópolis: Vozes, Bragança Paulista: EDUSF, 2005.

HABOWSKI, Adilson Cristiano; CONTE, Elaine; PUGENS, Natália Borba. A perspectiva da alteridade na educação. Conjectura: Filos. Educ., Caxias do Sul, v. 23, n. 1, p. 179-197, jan./abr. 2018. DOI: https://doi.org/10.18226/21784612.V23.N1.10

HABOWSKI, Adilson Cristiano. Teoria crítica da tecnologia e educação: desafios contemporâneos. 2019.153 f. Dissertação (Mestrado em Educação) - Universidade La Salle, Canoas, 2019. Disponível em: http://svrnet20.unilasalle.edu.br/bitstream/11690/1249/1/achabowski.pdf Acesso em: 18 nov. 2020

HARDAGH, Cláudia Coelho. Redes Sociais Virtuais: uma proposta de Escola Expandida. 2009. 157f. Tese (Doutorado em Educação) - Pontifícia Universidade Católica de São Paulo, São Paulo, 2009.

LOYOLA, Geraldo Freire. Me adiciona.com. Ensino de Arte+Tecnologias Contemporâneas+Escola Pública. 2009. 148f. Dissertação (Mestrado em Artes) Universidade Federal de Minas Gerais, Belo Horizonte, 2009.

PETRY, Luís Carlos. A im@gem pensa: aspectos quânticos da imagem cibernética. Revista Cibertextualidades, Universidade Fernando Pessoa, n. 3, p. 103-130, 2009.

ROCHA, Heloísa Vieira da; BARANAUSKAS, Maria Cecília Calani. Design e avaliação de interfaces humano-computador. São Paulo: USPIME, 2000.

ROSA, Maria Cristina da. A educação de professoras e professores de arte: construindo uma proposta de ensino multicultural a Distância. 2004. 187f. Tese (Doutorado em Engenharia de Produção) - Universidade Federal de Santa Catarina, Florianópolis, 2004.

SALLES, Beatriz. Rede social com música, arte e tecnologia. 2014. 171f. Tese (Doutorado em Arte) - Universidade de Brasília, Brasília, 2014.

SAMPAIO-RALHA, Jurema Luzia de Freitas. A utilização de linguagem VRML na Educação a distância em arte. 2003. 244f. Dissertação (Mestrado em Arte) - Universidade Estadual Paulista, São Paulo, 2003.

SANTOS, Cesar Augusto Baio. Da imersão à performatividade: vetores estéticos da obradispositivo. 2011. 219f. Tese (Doutorado em Comunicação e Semiótica) - Pontifícia Universidade Católica de São Paulo, São Paulo, 2011.

SANTOS, Moises Lucas dos. Arte-educação e tecnologia no ensino médio: reflexões a partir da proposta triangular. 2006. 162f. Dissertação (Mestrado em Artes) - Universidade de 
Brasília, Brasília, 2006.

SIQUEIRA, Paula Monteiro. Cinema digital e educação: novas formas de percepção Estética no século XXI. 2015. 143f. Dissertação (Mestrado em Educação) - Universidade Federal de São Carlos, São Carlos, 2015.

TURING, Alan Mathison. On computable numbers, with an application to the Entscheidungsproblem. Proceedings of the London Mathematical Society, v. 2, n. 42, p. 230-265, 1936.

XAVIER, Cleber Cardoso. Escolas parque de Brasília: uso do laboratório de informática pelos professores de arte. 2013. 150f. Dissertação (Mestrado em Arte) - Universidade de Brasília, Brasília, 2013.

\section{SOBRE OS AUTORES:}

\section{Carla Milbradt}

Mestre em Educação pela Universidade La Salle (2020). Participante do Núcleo de Estudos sobre Tecnologias na Educação - NETE/UNILASSALE/ CNPq. E-mail: cal_milbradt@hotmail.com

iD https://orcid.org/0000-0002-3608-6366

\section{Adilson Cristiano Habowski}

Doutorando em Educação pela Universidade La Salle - Canoas/RS, na linha de pesquisa: Culturas, Linguagens e Tecnologias na Educação. Mestre em Educação pela Universidade La Salle (2020). Participante do Núcleo de Estudos sobre Tecnologias na Educação NETE/UNILASALLE/CNPq. E-mail: adilsonhabowski@hotmail.com

iD https://orcid.org/0000-0002-5378-7981

\section{Elaine Conte}

Doutora em Educação pela Universidade Federal do Rio Grande do Sul (UFRGS). Professora do Programa de Pós-Graduação em Educação da Universidade La Salle (UNILASALLE). Líder do Núcleo de Estudos sobre Tecnologias na Educação - NETE/CNPq e membro do Grupo de Estudos sobre Filosofia da Educação e Formação de Professores -GEFFOP/CNPq. E-mail: elaine.conte@unilasalle.edu.br

iD https://orcid.org/0000-0002-0204-0757 